\title{
Aiming at a different View in Vascular Research
}

\author{
F Passariello* \\ *Fondazione Vasculab ONLUS, via Francesco Cilea 280 - 80127 Naples, Italy
}

submitted: Jul 6, 2016, accepted: Jul 6, 2016, EPub Ahead of Print: Nov 30, 2016, published: Dec 31, 2016

Conflict of interest: None

Corresponding author: Dr. Fausto Passariello, afunzionale@tiscalinet.it

(C) 2016 Fondazione Vasculab impresa sociale ONLUS. All rights reserved.

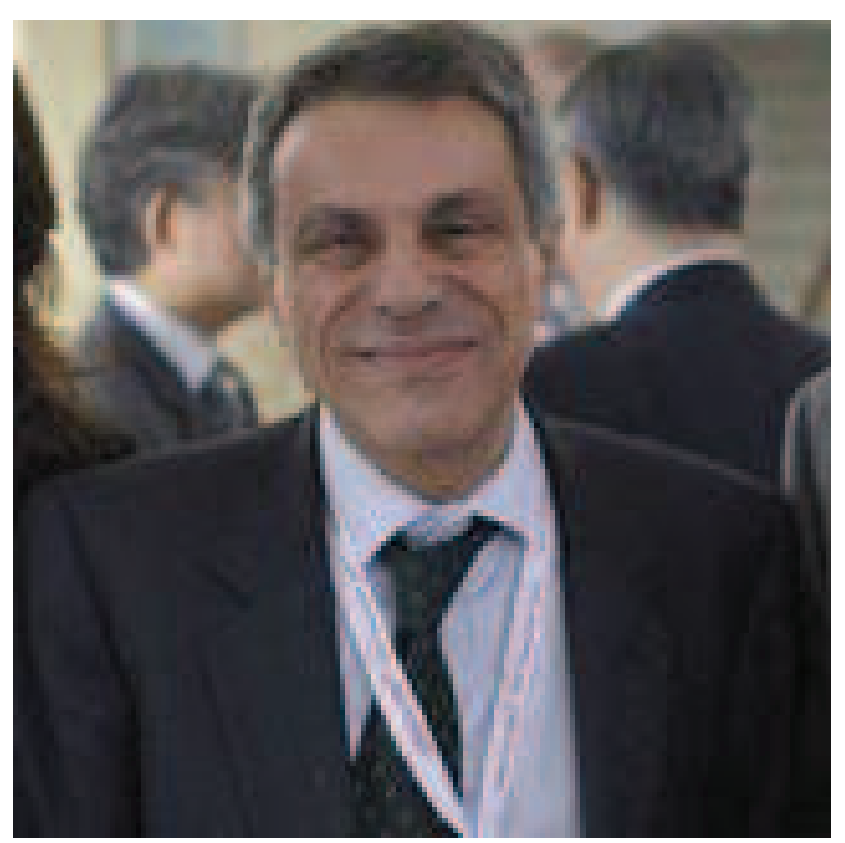

Fausto Passariello

Dear Readers and Researchers,

The Journal of Theoretical and Applied Vascular Research (JTAVR) aims at gathering contributes to vascular research, coming from biology, medicine and basic sciences like physics, fluid dynamics and bioengineering.

The journal is open also to the cultural aspects which lay behind our daily work, like models, epistemology, philosophy, history, in order to achieve a better comprehension of vascular phenomena.

As I often say, each patient who comes for a medical consultation deserves also a 3 minute, non-invasive and safe research work, privileging the cultural aspects and going far beyond our daily procedures, instead of stopping only at their material execution. Each patient indeed can teach us and being lazy in observing his/her data is an important loss and forever.

JTAVR has an online parallel voice in Vasculab, the Vascular List! (1990), which since 26 years is the most spread vascular list in the world. JTAVR is the Official Journal of the Vasculab Foundation ONLUS (2015), which aims to scientific research and to humanitarian missions. Vasculab, the Vasculab Foundation and JTAVR all three together share almost the same goals, of course with different realizations.

In addition, the journal strongly supports alternate non-animal models and any effort in order to Replace, Reduce and Refine (3Rs) the design of animal experiments.

The first issue of JTAVR is a practical example of this inter-disciplinary approach, covering almost all the topics cited above, as the Vasculab history and a general introduction to the 3 Rs argument. Treating the theoretical issue of vascular branching, several points of view are placed together from history of science to mathematics, from theoretical biology to microscopic and 3D anatomical reconstructions.

Using a wider eye/chakra, JTAVR accepts papers which could never find a place together in medical journals. We in the Editorial Team of JTAVR hope that this interdisciplinary environment will succeed in producing new interesting fruits in research.

\section{Fausto Passariello}

on behalf of the JTAVR Editorial Team. 